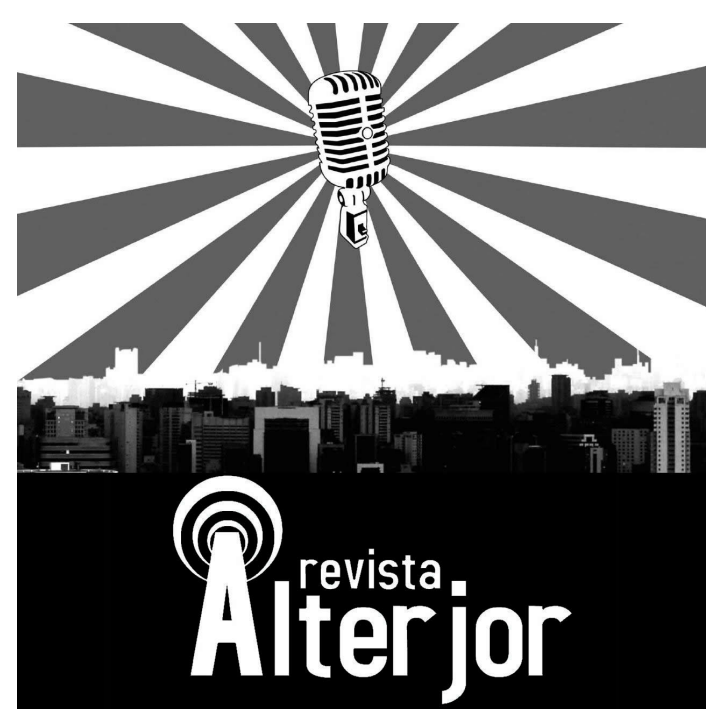

ESPAÇO ABERTO

\title{
PELO AMPLO DIREITO HUMANO À COMUNICAÇÃO: CRÍTICAS À PERSPECTIVA LEGAL INSTRUMENTALISTA DA RADIODIFUSÃO COMUNITÁRIA A PARTIR DE UM PANORAMA MUNDIAL
}

\section{João Paulo Malerba ${ }^{1}$}

RESUMO: O artigo se vale dos resultados de uma pesquisa comparativa legal mundial para tecer críticas a uma recorrente perspectiva restritiva e instrumentalista nas legislações de radiodifusão comunitária. Iniciamos com o histórico das recomendações legais internacionais sobre o setor em que já se observam contradições entre a compreensão ampla de direito humano à comunicação e indícios da defesa a tais meios condicionada a seu status legal, conteúdo e lugar social. Tais contradições se tornam ainda mais evidentes a partir das comparações de diferentes leis no mundo, normalmente resultantes de um poder disciplinador vertical e restritivo. Por fim, demonstramos que o mecanismo que condiciona o direito à comunicação das comunidades à critérios conteudísticos e de prestação de serviços tem como base um olhar elitista e preconceituoso acerca da radiodifusão comunitária e dos atores que a exercem.

PALAVRAS-CHAVE: direito à comunicação. Comunicação e cidadania. Legislação comparada. Rádio comunitária. Direitos humanos.

ABSTRACT: The article draws on the results of a comparative global legal research to criticize a recurring restrictive and instrumentalist approach in community broadcasting legislation. We begin with the history of the international legal recommendations on the sector in which there are already contradictions between the broad understanding of the human right to communication and evidence of the defence to such media conditioned to its legal status, content and social place. Such contradictions become even more evident from the comparisons of different laws in the world, usually resulting from a restrictive and vertical disciplinary power. Finally, we show that the mechanism that determines the right of community communication to content and service delivery criteria is based on an elitist and prejudiced view of community broadcasting and of the actors that carry it out.

\footnotetext{
${ }^{1}$ Professor e jornalista, é doutor em Comunicação e Cultura pela Escola de Comunicação da Universidade Federal do Rio de Janeiro (ECO/UFRJ), mestre e bacharel pela mesma instituição, tendo realizado parte de sua pesquisa de doutorado na University of Westminster (Londres, Reino Unido). Atualmente é professor substituto de radiojornalismo na Faculdade de Comunicação Social da Universidade do Estado do Rio de Janeiro (FCS/UERJ). E-mail: joaopaulomalerba@gmail.com
}

\section{Revista ALTERJOR}

Grupo de Estudos Alterjor: Jornalismo Popular e Alternativo (ECA-USP)

Ano 11 - Volume 02 - Edição 24 - Julho-Dezembro de 2021

Av. Professor Lúcio Martins Rodrigues, 443, Cidade Universitária, São Paulo, CEP: 05508-020 


\section{Anteier}

KEYWORDS: right to communication. communication and citizenship. comparative legislation. community radio. human rights.

\section{Considerações iniciais}

Desde aquelas consideradas pioneiras, que surgiram na primeira metade do século XX, na América Latina, as rádios comunitárias vêm assumindo uma diversidade de tipos e modos de ser, adequando-se e respondendo à realidade social, política e tecnológica do seu tempo e de suas comunidades. Presentes em todos os continentes, há emissoras rurais e urbanas, de baixíssima e alta potência, com ou sem outorga, transmitindo pelas ondas eletromagnéticas ou exclusivamente via web... Ao contrário do que se poderia deduzir, a convergência e a digitalização midiática apenas vieram aumentar sua relevância e garantir sua resiliência, ampliando alcance, renovando linguagens e fortalecendo seu propósito social. Afinal, apesar da variedade, há um razoável consenso de que os contornos de uma rádio comunitária são definidos pela participação de uma comunidade que, ao se apropriar do fazer-comunicacional, utiliza o veículo rádio com fins de mobilização e organização social, buscando alcançar maior poder político em suas demandas por direitos, inclusive e elementarmente, o direito à comunicação. Um dos objetivos deste texto é justamente argumentar que a importância das rádios comunitárias - para além do seu caráter instrumental ou de prestação de serviços - reside em sua capacidade de habilitar o poder de voz na coisa pública, um direito do qual depende os demais direitos.

A partir de uma análise comparativa com leis de radiodifusão comunitária de todo o mundo, realizada no marco de uma pesquisa de doutorado, o artigo critica uma perspectiva reducionista, funcionalista e condicionante para a justificativa da existência e relevância de tais atores. Tal pesquisa se valeu de ampla revisão bibliográfica, análise legal e documental internacional, amparadas por entrevistas, presencias e virtuais, semiestruturadas com radiodifusores comunitários, pesquisadores do campo da Comunicação Comunitária e ativistas pelo direito à comunicação.

\section{Revista ALTERJOR}

Grupo de Estudos Alterjor: Jornalismo Popular e Alternativo (ECA-USP)

Ano 11 - Volume 02 - Edição 24 - Julho-Dezembro de 2021 Av. Professor Lúcio Martins Rodrigues, 443, Cidade Universitária, São Paulo, CEP: 05508-020 


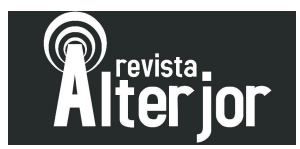

\section{Histórico das recomendações legais internacionais sobre radiodifusão comunitária}

Na opinião do secretário geral da Associação Mundial de Rádios Comunitárias (AMARC), o italiano Francesco Diasio, apesar de haver "claramente" um ambiente legal global mais favorável para as rádios comunitárias, com avanços em todos os continentes, ainda há "uma fratura muito forte entre as regulações, declarações e resoluções em nível internacional (...) e a situação ao nível nacional” (DIASIO, 2015).

De todo modo, os avanços, tímidos ou não, são sempre conquistados somente através da pressão interna de movimentos sociais nacionais, coordenada com articulações internacionais. Tais vozes amparam seu reclamo às garantias constitucionais com tratados, convenções e posicionamentos de órgãos internacionais a respeito da diversidade e pluralidade na comunicação e o papel que os meios comunitários exercem nesse sentido. Um primeiro ponto de partida é o da liberdade de expressão, garantida pelo artigo 19 da Declaração Universal dos Direitos Humanos (1948) e que "inclui a liberdade de, sem interferências, ter opiniões e de procurar, receber e transmitir informações e ideias por quaisquer meios"2. A amplitude de tal direito ultrapassa o caráter de prestadora de serviços à comunidade, que muitas vezes embasa a defesa das rádios comunitárias: aqui, a garantia da sua existência se insere no exercício de uma liberdade individual e coletiva que independe da chancela estatal.

Em plena Guerra Fria, nas décadas de 1960/70, no âmbito da UNESCO empreendeu-se uma rica discussão que colocava a comunicação como direito indispensável para o fortalecimento da e das democracias. Foi em meio a esse processo que acontece a Convenção Americana sobre Direitos Humanos, em São José de Costa Rica, em novembro de 1969 (inclusive, berço da Corte Interamericana de Direitos Humanos - CIDH). Sem prejuízos à soberania nacional, os países signatários garantiam o cumprimento do Pacto dela resultante sem poderem posteriormente dele esquivar-se, por exemplo, citando disposições do direito interno: na prática, porém, os casos de sua

\footnotetext{
${ }^{2}$ Disponível em https://www.unicef.org/brazil/declaracao-universal-dos-direitos-humanos. Acesso em 30.1.2021
}

\section{Revista ALTERJOR}

Grupo de Estudos Alterjor: Jornalismo Popular e Alternativo (ECA-USP)

Ano 11 - Volume 02 - Edição 24 - Julho-Dezembro de 2021 Av. Professor Lúcio Martins Rodrigues, 443, Cidade Universitária, São Paulo, CEP: 05508-020 


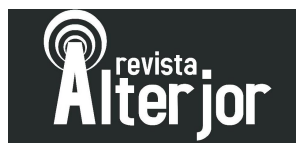

violação se acumulam. Não se pode negar, contudo, que ela se impôs como um importante parâmetro mínimo de proteção de direitos no continente. No caso da comunicação, garante, em seu Artigo 13, a "liberdade de pensamento e de expressão" e estabelece ainda que "não se pode restringir o direito de expressão por vias e meios indiretos, tais como o abuso de controles oficiais ou particulares (...) de frequências radioelétricas ou de equipamentos e aparelhos usados na difusão de informação"3. Anos depois, patrocinada pela UNESCO, no mesmo local é realizada a Primeira Conferência Intergovernamental sobre Politicas Nacionais de Comunicação na América Latina e Caribe, em julho de 1976. Ainda que não caibam aqui os detalhes, muitas polêmicas a antecederam, capitaneadas pela SIP (Sociedade Interamericana de Imprensa) e AIR (Associação Interamericana de Radiodifusão) e disseminadas pelas agências internacionais dos Estados Unidos e Europa acusando a UNESCO de tentar "estatizar a informação em cumplicidade com o Movimento dos Países não Alinhados e com a União Soviética" (QUIRÓS e SEGOVIA, 1996). Basicamente o teor da Conferência partia da percepção de desequilíbrio interno e externo dos fluxos comunicacionais, prescrevia a necessidade (de teor liberal, inclusive) de pluralismo e democracia na comunicação e apontava o papel do Estado como central para a mudança.

Mas o ápice dessa discussão e das polêmicas com os gigantes da comunicação foi o lançamento, também pela UNESCO, em 1980, de Um mundo e muitas vozes, também conhecido como Relatório MacBride, nome do jurista e jornalista irlandês que presidiu a comissão de alto nível que o produziu. Fruto de dois anos de intensos trabalhos e reconhecido como "o mais completo relato já produzido sobre a importância da comunicação na contemporaneidade" (RAMOS, 2005, p. 245), vemos ali aparecer o que tem embasado os atuais militantes pela democratização da mídia: uma concepção ampla do direito à comunicação, o colocando no centro e antecedente aos demais: "um processo bidirecional, cujos participantes - individuais ou coletivos - mantém um diálogo democrático e equilibrado. Essa ideia (...) é a própria base de muitas das ideias atuais que levam ao reconhecimento de novos direitos humanos" (UNESCO, 1983). Acontece que,

\footnotetext{
${ }^{3}$ Disponível em https://www.cidh.oas.org/basicos/portugues/c.convencao_americana.htm. Acesso em 30.1.2021
}

\section{Revista ALTERJOR}

Grupo de Estudos Alterjor: Jornalismo Popular e Alternativo (ECA-USP)

Ano 11 - Volume 02 - Edição 24 - Julho-Dezembro de 2021 Av. Professor Lúcio Martins Rodrigues, 443, Cidade Universitária, São Paulo, CEP: 05508-020 


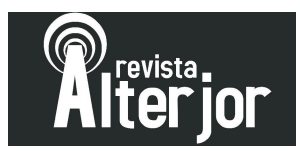

lido como uma proposta do Movimento dos Países não Alinhados, o Relatório apoiava a construção de uma "Nova Ordem Internacional da Informação e da Comunicação (NOMIC)" e desagradou sobremaneira uma então recém iniciada hegemonia neoliberal. Aquela concepção da comunicação se contrapunha frontalmente ao "consagrado, mas restritivo, direito à informação, do qual se beneficiava fundamentalmente a imprensa, enquanto instituição, e seus proprietários privados, como agentes privilegiados de projeção de poder sobre as sociedades" (RAMOS, 2005, p. 247). As conclusões do Relatório escancaravam um claro desequilíbrio de fluxos de informação se dando prioritariamente nos sentidos Norte/Sul e Oeste/Leste e recomendavam que os Estados se incumbissem de criar políticas públicas de promoção e respeito às culturas locais, garantindo o acesso igualitário aos meios de comunicação. Aquelas mesmas agências de notícias e atores internacionais, citados mais acima, centraram fogo numa argumentação idêntica e inversa: a interpretação do Relatório como uma ameaça à liberdade de imprensa e ao princípio do livre fluxo da informação, discurso até hoje repisado frente a qualquer tentativa de reequilíbrio no cenário midiático via regulação estatal. $\mathrm{O}$ resultado foi $\mathrm{o}$ sepultamento do Relatório MacBride e enfraquecimento daquele órgão da Organização das Nações Unidas (ONU) com a retirada da Inglaterra, de Thatcher, e os Estados Unidos da América, de Reagan. Desqualificada no tema da comunicação e sem recursos para levar adiante suas metas prioritárias, em 1987, a UNESCO retira de vez a NOMIC de sua pauta.

Mas o legado simbólico já estava consolidado. Era a primeira vez que o documento de um órgão internacional de tal envergadura tratava da comunicação em suas dimensões histórica, política e internacional. E o fazia sem perder de vista fenômenos já naquela época controversos como "televisão pornô" e "rádio pirata". Uma das recomendações do Relatório era o estímulo à participação coletiva na gestão midiática e o fomento ao que nomeava "comunicação alternativa". De acordo com Goés, os grupos dela participantes foram classificados pelo Relatório em: "oposição radical, de origem política, religiosa ou filosófica; movimentos de comunicação locais e comunitários; e os sindicatos ou outros grupos sociais que têm as suas próprias redes de comunicação" (2010, p. 12). Em comum, “o repúdio radical da corrente vertical dominante, o

\section{Revista ALTERJOR}

Grupo de Estudos Alterjor: Jornalismo Popular e Alternativo (ECA-USP)

Ano 11 - Volume 02 - Edição 24 - Julho-Dezembro de 2021 Av. Professor Lúcio Martins Rodrigues, 443, Cidade Universitária, São Paulo, CEP: 05508-020 


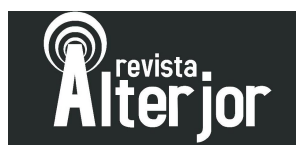

fortalecimento da coesão de certos grupos e a capacidade que oferece para o desenvolvimento das redes horizontais" (UNESCO, 1983).

Cronologicamente, veremos os acordos e declarações internacionais seguirem um caminho que parte do reconhecimento do direito à liberdade de expressão, passando pela ampliação do direito à comunicação e pelo incentivo ao pluralismo e diversidade na radiodifusão até o reconhecimento explícito e o incentivo à promoção dos meios comunitários. A Carta Europeia dos Direitos Humanos (novembro de 1950) ${ }^{4}$, Carta Africana de Direitos Humanos e dos Povos (junho de 1981) ${ }^{5}$ e a Convenção sobre os Direitos da Criança (novembro de 1989) ${ }^{6}$ vão reforçar a amplitude do direito à comunicação assegurada na Declaração Universal. A valorização da diversidade será o foco das propostas levantadas no Livro Verde sobre pluralidade e concentração dos meios de comunicação, da Comissão Europeia, em 1992, buscando "salvaguardar o pluralismo dos meios de comunicação e assegurar que estes continuem a ser livres e diversificados em todos os Estados-Membros" ". Sem ainda citar os meios comunitários, na Declaração Conjunta de 2001, Desafios à Liberdade de Expressão no Novo Século, os Relatores já chegariam a apontar que a diversidade implica "igualdade de oportunidades para o acesso de todos os segmentos da sociedade às ondas de radiodifusão" ${ }^{\text {. }}$.

Mas será a partir de 2002, em lugares do mundo onde a comunicação comunitária (particularmente a radiodifusão e ainda mais especificamente o rádio) assume papel de grande importância no desenvolvimento social, que iremos ter as menções explícitas à

\footnotetext{
${ }^{4}$ Disponível em http://www.echr.coe.int/Documents/Convention_POR.pdf . Acesso em 30.1.2021.

${ }^{5}$ Disponível em http://www.dhnet.org.br/direitos/sip/africa/banjul.htm . Acesso em 30.1.2021.

6 Disponível em https://www.unicef.org/brazil/convencao-sobre-os-direitos-da-crianca. Acesso em 30.1.2021.

${ }^{7}$ Comissão Europeia; Livro verde, "Pluralidade e concentração dos meios de comunicação no mercado interior; avaliação sobre a necessidade de uma ação comunitária"; Bruxelas, 23 de dezembro de 1992. Disponível em http://www.europarl.europa.eu/sides/getDoc.do?pubRef=-//EP//TEXT+MOTION+B52002-0590+0+DOC+XML+V0//PT. Acesso em 15.5.2016.

${ }^{8}$ Relator Especial das Nações Unidas para a Liberdade de Opinião e Expressão (ONU), Representante da Organização de Segurança e Cooperação na Europa para a Liberdade dos Meios de Comunicação (OSCE) e Relator Especial para a Liberdade de Expressão (OEA); "Mecanismos internacionais para a Promoção da Liberdade de Expressão - Declaração Conjunta Desafios à Liberdade de Expressão no Novo Século", 19 e 20 de novembro de 2001. Disponível em www.cidh.org/Relatoria. Acesso em 01.02.2021.
}

\section{Revista ALTERJOR}

Grupo de Estudos Alterjor: Jornalismo Popular e Alternativo (ECA-USP)

Ano 11 - Volume 02 - Edição 24 - Julho-Dezembro de 2021 Av. Professor Lúcio Martins Rodrigues, 443, Cidade Universitária, São Paulo, CEP: 05508-020 


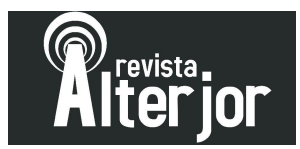

promoção desse setor. A Declaração de Princípios de Liberdade de Expressão adotada pela Comissão Africana dos Direitos Humanos e dos Povos em 2002 chama os Estados do continente a "assegurar uma equitativa atribuição de frequências entre emissores privados, tanto comunitários como comerciais" e proclama que "a radiodifusão comunitária deve ser promovida dado seu potencial de amplo acesso por comunidades pobres e rurais às ondas radioelétricas" "9. Também assumirão importância os subsequentes informes da Relatoria de Liberdade de Expressão da OEA, no sentido de reconhecer explicitamente o papel fundamental que cumprem os comunicadores comunitários e denunciar as regulamentações discriminatórias em diversos países da região. No Informe de 2002 lemos:

As rádios chamadas comunitárias, educativas, participativas, rurais, insurgentes, interativas, alternativas e cidadãs são, em muitos casos, e quando atuam no marco da legalidade ${ }^{10}$, as que ocupam os espaços que deixam os meios massivos; se erigem como meios que canalizam a expressão onde os integrantes do setor pobre costumam ter maiores oportunidades de acesso e participação em relação às possibilidades que poderiam ter nos meios tradicionais ${ }^{11}$ (grifo nosso).

Mas será com a importância da Relatoria Conjunta para Liberdade de Expressão englobando ONU, OEA (Organização dos Estados Americanos), AU (União Africana) e OSCE (Organização para a Segurança e Cooperação na Europa) que, em 2007, veremos recomendações acerca da radiodifusão comunitária aprofundarem suas necessidades reais junto aos Estados:

a radiodifusão comunitária deve estar expressamente reconhecida na lei com uma forma diferenciada de meios de comunicação, deve beneficiar-se de procedimentos equitativos e simples para a obtenção de licenças, não deve ter que cumprir com requisitos tecnológicos ou de

\footnotetext{
${ }^{9}$ Comissão Africana dos Direitos Humanos e dos Povos; "Declaração de Princípios de Liberdade de Expressão"; 2002. Disponível em www.achpr.org . Acesso em 01.02.2021.

${ }^{10} \mathrm{O}$ termo "no marco da legalidade" será repetido em todo o informe, tanto para distingui-las das rádios que não buscam outorga quanto para estimular o reconhecimento legal por parte dos Estados.

11 Relatoria Especial para a Liberdade de Expressão, Comissão Interamericana de Direitos Humanos (CIDH); Informe Anual 2002, Capítulo IV “Liberdade de expressão e pobreza". Disponível em www.cidh.org. Acesso em 01.02.2021.
}

\section{Revista ALTERJOR}

Grupo de Estudos Alterjor: Jornalismo Popular e Alternativo (ECA-USP)

Ano 11 - Volume 02 - Edição 24 - Julho-Dezembro de 2021 Av. Professor Lúcio Martins Rodrigues, 443, Cidade Universitária, São Paulo, CEP: 05508-020 


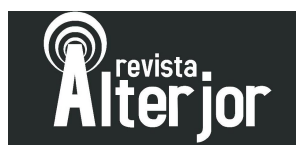

outra índole severos para a obtenção de licenças, deve beneficiar-se de tarifas de concessionária de licença e deve ter acesso a publicidade. (...) Os diferentes tipos de meios de comunicação - comerciais, de serviço público e comunitários - devem ser capazes de operar em, e ter acesso equitativo a todas as plataformas de transmissão disponíveis (LIGABO et all, 2007). ${ }^{12}$

No âmbito da sociedade civil, se destacam os 14 "Princípios para um marco regulatório democrático sobre rádio e TV comunitária” da AMARC: publicado em 2009 como resultado de uma pesquisa realizada em 29 países dos cinco continentes, orienta a elaboração e implementação de normas legais em radiodifusão comunitária compatíveis com os padrões internacionais de direitos humanos ${ }^{13}$.

Poderíamos seguir numa listagem exaustiva das últimas recomendações de organismos internacionais que incentivam os Estados a reconhecer e promover a radiodifusão comunitária como forma de aprofundar a democracia. De todo modo, podemos sintetizar que, de 2007 em diante, destaca-se a recorrência de elementos, como: o reconhecimento da existência de três setores na radiodifusão (privado, estatal e social sem fins de lucro); a necessidade de reserva equitativa do espectro para o setor comunitário; a garantia de condições de existência (inclusive quanto à possibilidade de publicidade e a necessidade de independência governamental); a possibilidade de acesso a todas as bandas de frequência (TV aberta e a cabo, AM, FM, OC etc.) e tecnologias, e; garantias da transição para o sistema digital terrestre. Isso representou o reconhecimento e a legitimação desses atores políticos em nível internacional. Mas, internamente, nos países, a adoção de tais recomendações continua encontrando resistência e preconceito por parcelas da sociedade e do próprio Estado.

\footnotetext{
${ }^{12}$ Relator Especial de Nações Unidas para a Liberdade de Opinião e Expressão (ONU), Representante da Organização de Segurança e Cooperação na Europa para a Liberdade dos Meios de Comunicação (OSCE), Relatora Especial da Comissão Africana de Direitos Humanos e dos Povos sobre Liberdade de Expressão e Acesso à Informação (CADHP) e Relator Especial para a Liberdade de Expressão da Organização dos Estados Americanos (OEA); "Declaração Conjunta"; dezembro de 2007, Op. cit.

${ }^{13}$ Disponível em http://www.amarcbrasil.org/amarc-principios-14-pontos-port.pdf. Acesso em 14.04.2015.
}

\section{Revista ALTERJOR}

Grupo de Estudos Alterjor: Jornalismo Popular e Alternativo (ECA-USP)

Ano 11 - Volume 02 - Edição 24 - Julho-Dezembro de 2021 Av. Professor Lúcio Martins Rodrigues, 443, Cidade Universitária, São Paulo, CEP: 05508-020 


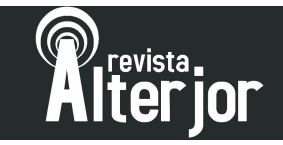

\section{Considerações comparativas da situação legal mundial da radiodifusão comunitária}

No balanço mundial realizado em 2011 para a UNESCO, o ex-presidente da AMARC, Steve Buckley, sintetiza que os marcos "legal, regulatório e de políticas públicas continuam sendo o obstáculo mais persistente" para o desenvolvimento da radiodifusão comunitária. Nesse sentido, o setor, em geral, encontra maiores desafios para se estabelecer em "condições onde a democracia e estado de direito é fraco ou onde os direitos humanos, incluindo a liberdade de expressão, não são respeitados". Do outro lado, lugares do mundo onde há "o aprofundamento da democracia e a adoção de uma abordagem de interesse público para o desenvolvimento de meios de comunicação livres, independentes e pluralistas" (BUCKLEY, 2011, p.11) tendem a ser mais favoráveis às comunitárias. Em diálogo com nossas pesquisas legais mundial, regional e do caso brasileiro, somos levados a concordar, mas levantar nuances às relações sugeridas por Buckley.

Sem dúvida, em ambientes não democráticos, as rádios comunitárias tendem a inexistir ou serem poucas e fugazes, devido à repressão sistemática, calcada na ausência de reconhecimento legal. Esse é o caso de países como China, Laos ou mesmo Brasil, no período da ditadura militar (1964-1985). Nesses cenários, a difícil conformação das rádios comunitárias tende a ser amparada por organismos internacionais (UNESCO, cooperação internacional, Igreja etc.) enquanto sua existência, conteúdo e capacidade de mobilização política são controlados pelo Estado (normalmente restringindo à prestação de serviços, como campanha de saúde, higiene etc.). Porém, casos como das rádios mineiras bolivianas, das comunitárias paraguaias contra a ditadura de Stroessner ou mesmo do movimento de rádios populares pré-democratização no Mali indicam que, mesmo sem exuberância numérica, suas ações podem ter a força necessária inclusive para desempenhar um papel importante no restabelecimento democrático.

Já em ambientes de democracia frágil (recente, em consolidação ou em risco), as rádios comunitárias encontram melhores condições para seu estabelecimento, mas, normalmente, carecem de um pleno reconhecimento legal e/ou veem ameaçada sua

\section{Revista ALTERJOR}

Grupo de Estudos Alterjor: Jornalismo Popular e Alternativo (ECA-USP)

Ano 11 - Volume 02 - Edição 24 - Julho-Dezembro de 2021 Av. Professor Lúcio Martins Rodrigues, 443, Cidade Universitária, São Paulo, CEP: 05508-020 


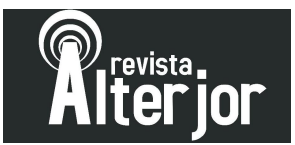

autonomia. A ausência ou insuficiência legal dão base para a deslegitimação social e para a perseguição estatal, dificultando mais esse espaço de fortalecimento da sociedade civil, como foi o caso das rádios comunitárias salvadorenhas pós-democratização (ausência legal e campanha difamatória) e a perseguição às emissoras indonésias pós-Soeharto (lei impeditiva empurrando para a ilegalidade). Já o ataque à autonomia normalmente acontece por um processo, via Estado, de descaracterização (externa) ou cooptação (interna). O caso angolano demonstra essa tentativa de verniz democrático ao chamar de "comunitárias" as novas rádios estatais locais, cujos conteúdo, pessoal e equipamento são, na verdade, fornecidos pela Rádio Nacional de Angola (estatal).

Quando em ambientes de democracia consolidada, é mais raro que as rádios comunitárias não sejam legalmente reconhecidas pelo Estado e a sua autonomia tende a ser amparada e garantida por uma sociedade civil pujante. Porém, a maturidade democrática não garante vitalidade do setor, fim da repressão ou ausência de retrocessos para as rádios comunitárias. É bem verdade que os melhores exemplos de cenários legais e de políticas públicas favoráveis às rádios comunitárias são encontrados em países de democracia robusta, como Austrália, Canadá, Irlanda, França, Holanda e Uruguai. Mas vimos um país como a Espanha impor um ambiente legal bastante restritivo para suas rádios comunitárias. Nesse sentido, é simbólico o caso dos Estados Unidos da América: arvorado bastião mundial da democracia e da liberdade de expressão, suas antigas rádios comunitárias amargaram décadas de políticas de comunicação privatistas e superconcentradoras: nascidas em 1949, foram varridas do dial em 1978, depois precariamente reconhecidas em 2000 e, somente em 2011, viram derrubadas as limitação de potência e o impedimento a operar em centros urbanos. Além de não podermos fazer uma relação direta entre consolidação da democracia e ambiente favorável às rádios comunitárias, devemos relativizar o papel que o próprio status legal desempenha na vitalidade desses atores. A partir de uma análise regional, Gustavo Gomez, diretor do Observacom (Uruguai), em sua fala no Seminário Internacional Comunicación Comunitaria para el Nuevo Siglo, realizado em setembro de 2015, no Chile, aponta haver, recentemente, um ambiente legal mais favorável para as rádios comunitárias latino-americanas. Porém, afirma que "a legislação é importante, mas não

\section{Revista ALTERJOR}

Grupo de Estudos Alterjor: Jornalismo Popular e Alternativo (ECA-USP)

Ano 11 - Volume 02 - Edição 24 - Julho-Dezembro de 2021 Av. Professor Lúcio Martins Rodrigues, 443, Cidade Universitária, São Paulo, CEP: 05508-020 


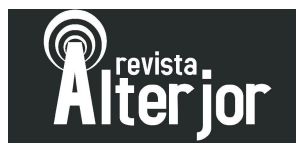

suficiente", avaliando que o pleno desenvolvimento do setor depende de como se aplica a lei, quais os seus objetivos, as políticas públicas e como os meios comunitários delas se apropriam. E os exemplos regionais de leis consideradas positivas comprovam a ressalva de Gomez: a Colômbia, a referência latino-americana legal mais antiga (inclusive, modelo para o movimento brasileiro pró-legalização das rádios comunitárias de meados de 1990) e exemplo atual de política pública efetiva para o setor, demorou onze anos para lançar editais de outorga para grandes cidades, e só o fez sob o peso de uma sentença da Corte Constitucional. Outro caso emblemático é a da internacionalmente elogiada lei argentina de meios: antes de ser erodida pelo governo do ex-presidente Macri, sua aplicação havia sido insuficiente, também no que concerne aos meios comunitários. E isso não aconteceu pela (já esperada) judicialização empreendida pelas emissoras comerciais: o "fogo amigo" veio das próprias autoridades argentinas que garantiram sua presença somente em cidades sem conflito de espectro por naturalizarem uma ideia de rádio comunitária " $P P P$ - pequenas, poucas e pobres", para usar um termo recorrente no movimento latino-americano.

Como se pode desconfiar, nada garante um ambiente político-estatal favorável e sem retrocessos para as rádios comunitárias. $\mathrm{Na}$ verdade, em se tratando da sua relação com o Estado, as rádios comunitárias vivem em crise permanente: seja antes ou depois de estabelecido um marco legal nacional.

\section{Sobre os impactos limitadores das leis de radiodifusão comunitária}

Há um enquadramento inerente a qualquer solução estatal. No histórico caso francês, isso foi bem apontado por Félix Guattari, filósofo e militante das mundialmente emblemáticas rádios livres francesas das décadas de 1970-80. Ele nos conta que, após anos de desobediência civil e repressão estatal, através de portaria, o então presidente socialista François Mitterrand deixara "fazer rádios livres numa boa, só que” com limite de alcance, proibição de formação de redes, exigência de estatuto de associação sem fins de lucro e subvenção estatal condicionada a um mínimo de audiência, qualidade e

\section{Revista ALTERJOR}

Grupo de Estudos Alterjor: Jornalismo Popular e Alternativo (ECA-USP)

Ano 11 - Volume 02 - Edição 24 - Julho-Dezembro de 2021 Av. Professor Lúcio Martins Rodrigues, 443, Cidade Universitária, São Paulo, CEP: 05508-020 


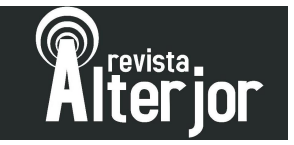

utilidade social: "o poder assim ataca o miolo dessas rádios, fazendo com que se tenda a reproduzir o sistema antigo" (GUATTARI e ROLNIK, 1986, p. 113).

No processo de legalização, ao longo das negociações com os demais setores da sociedade, um modelo de rádio comunitária sempre se impõe, seja pela força política de seus atores, seja por melhor caber no novo rearranjo legal: além de matar os demais modelos incipientes, gera um efeito abortivo no que de novo poderia surgir. Nesse sentido, são raros os casos de leis complexas e abrangentes como a canadense, que prevê não menos que quatro tipos (e subtipos) de outorga, acesso a todas as bandas, possibilidade de licenças temporárias, múltiplas de financiamento, inclusive, garantindo fundo público. Ou de países como Tailândia e Uruguai, que preveem a possibilidade de reconhecer uma entidade não legalmente estabelecida como detentora de uma outorga (MENDEL, 2013, p. 54).

Não sendo o caso francês exceção, muitas leis surgem para conter a força das rádios comunitárias: é o caso chileno, mexicano, indiano, peruano e, até pouco tempo, o estadunidense. Nesse sentido, a lei brasileira é paradigmática (cf. AUTOR): conquistada a duras penas, dilapidada por forças opositoras e aceita como "lei mínima"14, o que se conseguiu com a legalização em 1998 foi o modelo de radiodifusão comunitária mais restritivo da América do Sul (cf. AUTOR) e que permanece inalterado depois de duas décadas de luta da sociedade civil e vigilância atenta dos radiodifusores comerciais e seus aliados políticos. Apesar de dezenas propostas de alterações legais no parlamento brasileiro, inclusive majoritariamente favoráveis, nenhuma mudança significativa se deu e mesmo as melhorias mais tímidas por parte do Executivo foram barradas. $\mathrm{O}$ mesmo aconteceu em El Salvador quando os parlamentares consultaram primeiro os radiodifusores comerciais acerca de uma proposta de lei de radiodifusão comunitária para, então, rechaçá-la. Ou na campanha mentirosa de 2000 da National Association of

\footnotetext{
${ }^{14}$ Esse foi o termo utilizado por José Sóter, que por anos foi coordenador executivo da ABRAÇO e que participou do processo de negociação no Congresso para a aprovação da Lei 9612: "aceitamos a negociação tendo-a como lei mínima, apenas para criar o serviço de radiodifusão comunitária e as comunidades pudessem sair da ilegalidade imposta pelo governo". Disponível em: http://www.agenciaabraco.org/site/perseguicao-a-criminalizacao-das-radios-comunitarias-por-filiacaopartidaria/. Acesso em 18.6.2016.
}

\section{Revista ALTERJOR}

Grupo de Estudos Alterjor: Jornalismo Popular e Alternativo (ECA-USP)

Ano 11 - Volume 02 - Edição 24 - Julho-Dezembro de 2021 Av. Professor Lúcio Martins Rodrigues, 443, Cidade Universitária, São Paulo, CEP: 05508-020 


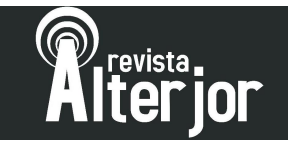

Broadcasters advogando no congresso americano que as Low Power FMs (nome dadas às rádios comunitárias estadunidenses) iriam levar ao "caos no ar", por conta de interferências. O padrão se repete em muitos lugares do mundo: o modelo privatista e barganhista de gestão do espectro eletromagnético perpetuado por relações espúrias público-privado fazendo do Estado o escritório executivo das classes hegemônicas. Dessa forma, o que era "lei mínima" perdura mais que o esperado e, ainda que sistematicamente contestada, vai deixando seus estragos enquanto modelo socialmente aceito. Inclusive pelas próprias rádios comunitárias.

Isso se deve ao delicado processo normativo (formador, modelador, definidor) que decorre de qualquer lei: a tendência de o legal se amalgamar ao legítimo e, com o passar do tempo, naturalizar-se como modelo único.

A lógica circular do poder disciplinar estatal que ajuda a empurrar as comunitárias para a solução legal única é também alimentada por um abrangente e eficiente aparelho repressor. Independentemente da situação legal, coincide em todos os países do mundo a conformação de um aparato persecutório, policial e simbólico, normalmente bem estruturado e atento a qualquer atividade não autorizada de radiodifusão resultando na apreensão de equipamentos e/ou criminalização dos comunicadores populares.

O fechamento e o sequestro dos aparelhos, por si só, pode representar um duro baque no ânimo de uma comunidade em fazer uso de seu direito à comunicação. Como se não bastasse, países como o Brasil, México, Chile e Guatemala, ainda lançam mão também de leis penais para inibir qualquer uso não previsto do espectro eletromagnético. A penalização da radiodifusão sem licença é um recurso veementemente desencorajado pelos padrões internacionais de direitos humanos, dado o seu forte poder inibidor: tratase de uma medida desproporcional e, na prática, desnecessária, já que todos os países citados já possuem mecanismos alternativos e civis para controlar o uso das frequências radioelétricas. Conclui-se ser recurso pleonástico cujo objetivo final é criminalizar a radiodifusão popular como um todo, mantendo inalterado o cenário concentrador e privatista das telecomunicações.

\section{Revista ALTERJOR}

Grupo de Estudos Alterjor: Jornalismo Popular e Alternativo (ECA-USP)

Ano 11 - Volume 02 - Edição 24 - Julho-Dezembro de 2021 Av. Professor Lúcio Martins Rodrigues, 443, Cidade Universitária, São Paulo, CEP: 05508-020 


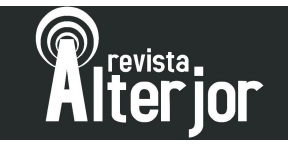

5. Sobre a visão legal instrumentalista e preconceituosa da radiodifusão comunitária

A criminalização é discursivamente colada ao lugar social dos que fazem uso desse meio de comunicação popular: normalmente, minorias (Europa) e/ou periferias (América Latina). Ao tratar da ideia de minoria, Sodré destaca sua referência topológica, como o "conceito de um lugar onde se produz um fluxo de discursos e ações com o objetivo de transformar um determinado ordenamento fixado no nível de instituições e organizações" (SODRÉ, 2005, p. 11). Já na abordagem realizada por Milton Santos, periferia é o lugar onde o cidadão é duplamente penalizado: ao estigma resultante da segmentação de classe social se soma o modo territorial de distinção e desigualdade (SANTOS, 2007). A reivindicação por um terceiro setor na comunicação parte, mormente, de um lugar social cujo caráter de luta e privação corrobora para fazer parecer ser concessão (do rentável espectro radioelétrico) o que, na verdade, deveria ser compreendido como a efetivação de um direito (humano e amplo à comunicação): o que há de reclamar aquele que, não tendo nada, é-lhe concedido um pouco? O resultado é quase sempre uma lei remendo (ou "lei mínima”), em seu modelo mais inócuo possível, já que, por conta da repressão, "ruim com ela, pior sem ela". O que se nota do panorama mundial é que tendem a ser mais favoráveis às rádios comunitárias as inovações legais que as reconhecem reformando o sistema como um todo, através de uma lei geral de comunicações, como foi o caso da Argentina, Bolívia, Equador e Irlanda, em que foi reestruturada a divisão do espectro eletromagnético sob os princípios de igualdade e pluralidade, com (caso dos três primeiros) ou sem reserva de espectro (caso irlandês). $\mathrm{O}$ grifo anterior é porque tudo depende da constelação de forças sociais do momento: enquanto a lei uruguaia de rádio comunitária (2007) é exemplar e antecede a aprovação da lei geral (2014), a reforma geral da lei de comunicação espanhola (2010) piorou a situação das suas comunitárias.

Na maioria dos países, o modelo/parâmetro legal resultante, além de ter de caber nos restos não valorizados do espectro eletromagnético, deve ser aceito e justificável para o restante da sociedade. Chegamos aqui a mais uma implicação da legalidade à autonomia das rádios comunitárias: a concessão de um direito desde que com uma função.

\section{Revista ALTERJOR}

Grupo de Estudos Alterjor: Jornalismo Popular e Alternativo (ECA-USP)

Ano 11 - Volume 02 - Edição 24 - Julho-Dezembro de 2021 Av. Professor Lúcio Martins Rodrigues, 443, Cidade Universitária, São Paulo, CEP: 05508-020 


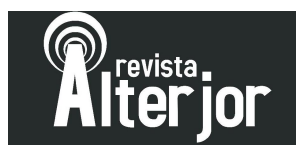

No estudo Tuning into development: International comparative survey of community broadcasting regulation ("Sintonizando o desenvolvimento: estudo comparativo internacional de regulação em radiodifusão comunitária”, em tradução livre), depois de analisar mais de 30 países $^{15}$, Mendel (2013) divide os tipos de definições legais em três áreas principais: a) forma (quanto à estrutura do radiodifusor), em que nota uma quase ubiquidade quanto à exigência de se tratar de uma entidade sem fins de lucro; b) vínculo com a comunidade: todos os países reconhecem comunidades geográficas, mas nem todos comunidades de interesse, e; c) padrões de conteúdos positivos (p. ex., relevância comunitária), sendo comum exigir que o conteúdo sirva às necessidades da comunidade, priorizando educação, informação e o desenvolvimento. É revelador analisar padrões que aparecem numa análise tão ampla e diversa como a empreendida por Mendel, dando conta de legislações antigas (Canadá e França) e recentes (Uruguai e Hungria) em contextos cuja diversidade vai do Butão à Suécia.

Quanto à forma (a), não surpreende aquela ubiquidade verificada, pois a ausência de fins de lucro vai ao encontro do que primeiro distingue a comunicação comunitária das demais modalidades de comunicação (a lei de rádio comunitária japonesa é uma das raras exceções por conceder outorgas para atores com fins de lucro). Essa delimitação é importante para preservar um ator de existência frágil como a rádio comunitária: definições muito amplas ou muito restritas podem lançá-las numa competição desleal que podem descaracterizá-las ou mesmo extingui-las.

Também a questão da relação com a comunidade (b) tem sido considerada a pedra fundamental por todos os pesquisadores que se debruçaram sobre o tema. Mas aí já encontramos indícios do formalismo (inevitável?) da lei. Tendo em vista a natureza tecnológica do rádio hertziano faz sentido que as legislações reconheçam como legítima a comunidade geográfica. Porém, o fato que nem todas as leis legitimem a comunidade de interesse dá pistas de sua motivação limitadora. Na comparação que fizemos das

\footnotetext{
${ }^{15}$ Os países analisados foram Argentina, Austrália, Bangladesh, Benin, Butão, Bolívia, Brasil, Canadá, Colômbia, Dinamarca, Etiópia, França, Hungria, Índia, Indonésia, Maldivas, Mali, Mongólia Moçambique, Mianmar, Nepal, Nigéria, Filipinas, Sérvia, Ilhas Salomão, África do Sul, Espanha, Suécia, Tailândia, Uganda e Uruguai.
}

\section{Revista ALTERJOR}

Grupo de Estudos Alterjor: Jornalismo Popular e Alternativo (ECA-USP)

Ano 11 - Volume 02 - Edição 24 - Julho-Dezembro de 2021 Av. Professor Lúcio Martins Rodrigues, 443, Cidade Universitária, São Paulo, CEP: 05508-020 


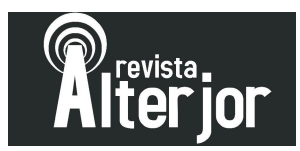

legislações de todos os países da América do Sul (AUTOR), verificamos que "excetuando Argentina, Equador e Uruguai, todas as demais leis vinculam comunidade a um espaço territorial demarcado, o que se assevera com limitações de potência e alcance", nos levando a "desconfiar dos interesses ocultos em tal atrelamento comunidade \& território fisico quando justamente os marcos legais que aceitam uma maior amplitude do conceito são aqueles que menos impõem restrições aos meios comunitários" (p. 10-11). No caso brasileiro, logo em seu primeiro artigo, de definição, a lei apressa-se a limitar o serviço a "bairros e vilas", distanciando o problema das rádios comunitárias dos centros urbanos. E essa percepção não é exclusiva dos reguladores brasileiros: no caso estadunidense, até 2011 conseguiu-se restringir as comunitárias ao meio rural; também não foi outro o enfoque das autoridades argentinas de aplicação da Ley de Medios quando concentraram a concessão de outorga para as comunitárias às localidades de baixa disputa pelo espectro.

Porém, o que mais nos chama à atenção na análise mundial de Mendel é a recorrência de uma exigência conteudística (c), que "sirva" à comunidade e esteja voltada para o "desenvolvimento local". Notemos que o direito humano à comunicação, que deveria ser garantido de forma ampla e irrestrita, no caso do setor comunitário (e somente nele), tende a ser condicionado a sua utilidade social (prestação de serviços, utilidade pública etc.). Isso fica explícito no caso japonês, onde as melhoras legais e o aumento do apoio estatal foram se dando de acordo com que se percebia a importância das comunitárias na prevenção e mitigação de danos em desastres naturais, como recorrentes terremotos e tsunamis. Seus desdobramentos evidenciam o risco quando se condiciona um direito à sua função instrumental: num dos poucos casos mundiais legais que abarcam também atores com fins de lucro, os recentes cortes de investimentos e o aumento das exigências atingiram primeiro as rádios comunitárias japonesas sem fins de lucro. (Afinal, instrumentos, depois de utilizados para os seus fins, costumam ficar esquecidos até que sejam novamente necessários). Ainda que a maioria das leis nacionais vincule qualquer concessão (comercial, educativa etc.) do espaço radioelétrico a finalidades culturais, sociais e informativas, nenhuma sofre o rigor da vigilância conteudística estatal e da sociedade (sem falar dos próprios pares) como a comunitária.

\section{Revista ALTERJOR}

Grupo de Estudos Alterjor: Jornalismo Popular e Alternativo (ECA-USP)

Ano 11 - Volume 02 - Edição 24 - Julho-Dezembro de 2021 Av. Professor Lúcio Martins Rodrigues, 443, Cidade Universitária, São Paulo, CEP: 05508-020 


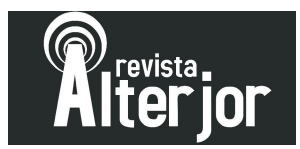

\section{Considerações finais}

O mecanismo que condiciona o direito à comunicação das comunidades ao modo como é exercido tem como base uma abordagem legalista e instrumentalista da radiodifusão comunitária, por sua vez, alimentada por um olhar elitista e preconceituoso acerca dos atores que a exercem. Encarados como cidadãos de segunda ordem pelo lugar social que ocupam (camponeses, imigrantes, favelados etc.), os que reivindicam um quinhão do disputado espaço eletromagnético só o merecem quando demonstram fazer dele um uso justificável e insuspeito.

Essa visão instrumental e restritiva da radiodifusão comunitária pode ser verificada na sociedade como um todo, mas fica ainda mais evidente (porque cristalizado em leis, métodos e ações) no Estado. Exemplificamos com o caso brasileiro:

a) No âmbito do Judiciário segue essa linha já na primeira sentença favorável à radiodifusão comunitária que se tem conhecimento. Em 1994, antes da legalização das rádios comunitárias brasileiras, o juiz Casem Mazloum abriu importante jurisprudência com o caso da Rádio Reversão, não somente inocentando seu diretor como permitindo a continuidade do funcionamento da emissora. Porém, ainda que tenho feito referência ao monopólio das comunicações e ao autoritarismo do marco legal, sua sentença se embasou na "reduzida potência" de uma emissora destinada "a atividades culturais e no contexto de tais fins" (COELHO NETO, 2002, p. 201);

b) Isso permanece em jurisprudências mais recentes, inclusive naquelas sugeridas pela sociedade civil: com objetivo de afastar a incidência da legislação criminal e trazer para o âmbito civil ou administrativo, a ONG Artigo 19, que atua pela liberdade de expressão em todo o mundo, compilou um manual prático com uma série de argumentos a serem usados na defesa jurídica de acusados pelo uso não autorizado do espectro eletromagnético: "Defesa da liberdade de expressão das rádios comunitárias no Brasil: teses jurídicas aplicáveis”. Entre as teses jurídicas

\section{Revista ALTERJOR}

Grupo de Estudos Alterjor: Jornalismo Popular e Alternativo (ECA-USP)

Ano 11 - Volume 02 - Edição 24 - Julho-Dezembro de 2021 Av. Professor Lúcio Martins Rodrigues, 443, Cidade Universitária, São Paulo, CEP: 05508-020 


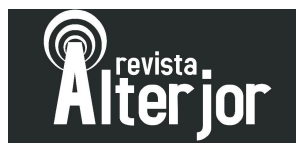

aplicáveis à defesa das rádios comunitárias, até mesmo a que versa sobre o "exercício regular do direito à liberdade de expressão" recorre ao argumento do "importante papel de interesse público nas comunidades nas quais estão inseridas", elencando prestação de serviços, comunicados de utilidade pública etc. (ARTIGO 19, 2016, p. 43-48).

c) No Legislativo, a lei brasileira de radiodifusão comunitária, quando fala das finalidades do serviço (art. 3), nos parece simbólico que a menção a "prestar serviços de utilidade pública" (III) apareça antes da "capacitação dos cidadãos no exercício do direito de expressão" (V) (BRASIL, 1998);

d) Na esfera do Executivo, até 2015, entre o calhamaço burocrático exigido aos outorgantes de rádio comunitária estavam a "declaração, assinada por todos os diretores, comprometendo-se ao fiel cumprimento das normas estabelecidas" e a "certidão de setores de distribuição dos foros criminais dos lugares em que cada dirigente tenha residido" que "servirão ao exame da idoneidade da entidade interessada e de seus dirigentes", a quem se suspeita inidôneo até que se comprove o contrário;

e) No âmbito do Aparato regulatório e repressor, a criminalização da radiodifusão comunitária anda de mãos dadas à criminalização da pobreza: no Relatório Gerencial 2009 da Superintendência de Radiofrequência e Fiscalização da Anatel (Agência Nacional de Telecomunicações), rádio clandestina e comunitária são tratadas como sinônimos, apontando tais operações como "normalmente cercadas de riscos e desafios, devido às áreas onde muitas delas estão localizadas" (ANATEL, 2009, p. 38). Nem precisaria o Relatório estar ilustrado com fotos de comunidades ribeirinhas e favelas urbanas para delinearmos as sinapses que conectam clandestinidade, rádio comunitária e pobreza.

Como último exemplo, e voltando para a esfera das recomendações internacionais, parece ser sintomático que a primeira menção explícita do setor comunitário num documento do porte da Relatoria de Liberdade de Expressão da OEA já descreva as rádios comunitárias como canais onde os "integrantes do setor pobre" podem ocupar "os espaços

\section{Revista ALTERJOR}

Grupo de Estudos Alterjor: Jornalismo Popular e Alternativo (ECA-USP)

Ano 11 - Volume 02 - Edição 24 - Julho-Dezembro de 2021 Av. Professor Lúcio Martins Rodrigues, 443, Cidade Universitária, São Paulo, CEP: 05508-020 


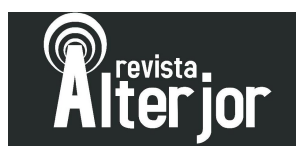

que deixam os meios massivos", além de restringir seu valor à atuação "no marco da legalidade" (cf. nota 9). É certo haver evidências de que ilegalidade não é sinônimo de independência e as experiências internacionais demonstram que a possibilidade de cooptação pode ser maior nas ausências ou afrouxamentos legais. Mendel aponta os riscos em que se encontram os princípios e as práticas das rádios comunitárias nepalesas: a falta de padrões regulatórios claros tem favorecido a comercialização e a partidarização política das rádios (2013, p. 36). Ou o caso de Honduras, em que a ausência legal foi usada pelo governo golpista de Sosa para "negociar" e cooptar algumas rádios comunitárias por meio de um decreto presidencial, à revelia da consolidação de uma lei. Além do mais, nem sempre a situação política e social permite soluções alegais, sem amparo institucional e/ou jurídico, como em áreas de conflito social (favelas dominadas por tráfico de drogas, áreas em litígios fundiários, bairro sob o domínio de milícias etc.) e/ou quando se confrontam com poderes locais e regionais.

O que pudemos concluir de nossa análise mundial da situação legal das rádios comunitárias é que não deveria ser preciso escolher entre legalidade ou ilegalidade: se há situações sociais que exigem proteção jurídico-estatal e se há demanda social por não institucionalidade, as leis deveriam (e poderiam) contemplar a diversidade de formatos. Porém, para tal, precisam abandonar tanto uma política privatista de concessão de outorgas de radiodifusão quanto uma perspectiva limitadora, preconceituosa e instrumentalista das mídias comunitárias e de seus fazedores. Uma solução possível, por exemplo, é reservar faixas do espectro eletromagnético para a gestão autônoma da sociedade civil. De fato, esse é um movimento ascendente no direito humano à comunicação, a demanda pelo uso não licenciado e não comercial de partes de todas as faixas do espectro, o chamado movimento pelo espectro livre, alvo de nossas investigações atuais.

\section{Revista ALTERJOR}

Grupo de Estudos Alterjor: Jornalismo Popular e Alternativo (ECA-USP)

Ano 11 - Volume 02 - Edição 24 - Julho-Dezembro de 2021 Av. Professor Lúcio Martins Rodrigues, 443, Cidade Universitária, São Paulo, CEP: 05508-020 


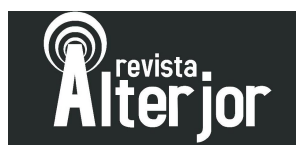

\section{Referências}

ANATEL. Relatório Anual. Brasília, 2009. Disponível em www.anatel.gov.br/Portal/exibirPortalRedireciona.do?codigoDocumento=246044. Acesso em 01.2.2021.

ARTIGO 19. Defesa da liberdade de expressão das rádios comunitárias do Brasil: teses aplicáveis, 2016. Disponível em: http://artigo19.org/?p=7474. Acesso em 01.02.2021.

BRASIL, Lei 9.612, de 1998. Institui o Serviço de Radiodifusão Comunitária e dá outras providências.

BUCKLEY, S. Community Media:a good practice handbook. Paris: Unesco, 2011.

COELHO NETO, A.. Rádio Comunitária Não é Crime: Direito de Antena: O Espectro Eletromagnético como um Bem Difuso. São Paulo: Ícone, 2002.

DIASIO, F. Entrevista sobre a AMARC Mundial. Santiago (Chile), 2015. Entrevista concedida a Autor em 30 de maio de 2015.

GOÉS, L. T. Relatório MacBride - 30 anos: concentração midiática, mídia alternativa e Internet. In: Revista PJ: Br - Jornalismo brasileiro, out. 2010. Disponível em: www2.eca.usp.br/pjbr/arquivos/artigos13b.htm. Acesso em 01.2.2021.

GUATARRI, F. e ROLNIK, S. Micropolítica: cartografias do desejo. Petrópolis: Vozes, 1986.

MENDEL, T. Tuning into development: an international comparative survey of community broadcasting regulation. Paris: United Nations Educational, Scientific and Cultural Organisation, 2013.

SANTOS, M. O Espaço do cidadão. São Paulo: Edusp, 2007.

SODRÉ, M. As estratégias sensíveis: afeto, mídia e política. Petrópolis: Vozes, 2006.

RAMOS, M. C. Comunicação, direitos sociais e políticas públicas. In: MARQUES DE MELO, J.; SATHLER, L. Direitos à Comunicação na Sociedade da Informação. São Bernardo do Campo, SP: UMESP, 2005.

UNESCO. Um mundo, muitas vozes (Relatório MacBride). Rio de Janeiro: FGV, 1983.

Revista ALTERJOR

Grupo de Estudos Alterjor: Jornalismo Popular e Alternativo (ECA-USP)

Ano 11 - Volume 02 - Edição 24 - Julho-Dezembro de 2021 